\title{
Influência do ambiente na criação de codornas de corte: Revisão
}

\author{
Dihego S. Bonfim ${ }^{1 *}$; Solange de Araújo Melo²
}

${ }^{1}$ Mestrando do Programa de Pós graduação em Ciência Animal, Universidade Federal do Maranhão, Chapadinha, Maranhão.

${ }^{2}$ Professora Dra. da Universidade Estadual do Maranhão, Balsas, Maranhão.

*Autor para correspondência, E-mail: dihegozootecnia@hotmail.com

RESUMO. Objetivou- se com este artigo revisar a influência que o ambiente exerce na criação de codornas de corte. O bem estar animal tem ocupado lugar de destaque nos criatórios uma vez que situações de estresse levam a um estado fisiológico que é caracterizado como indesejável. A temperatura e o microclima no sistema de criação podem ser considerados como fatores físicos de maior efeito sobre o crescimento das codornas, influenciando diretamente sobre o aproveitamento do alimento. Animais estressados termicamente não conseguem aproveitar de forma eficiente os nutrientes oferecidos pela alimentação, diminuindo o consumo de ração. Para avaliar o ambiente térmico em que os animais estão expostos, utiliza-se o Índice de Temperatura de Globo Negro e Umidade. Oscilações nos índices de temperatura e umidade, provocadas pelas condições ambientais, refletem na alteração da temperatura superficial média modificando a resposta fisiológica do animal. A temperatura cloacal das aves também pode ser uma medida interpretada para identificar condições de conforto ou estresse térmico, representando a temperatura do núcleo corporal. Durante o estresse por calor, ocorrem reajustes fisiológicos, hormonais e moleculares, causando modificações na função e na estrutura das células.

Palavras-Chave: Coturnicultura, conforto térmico, desempenho, produção.

\section{Environmental effect on the creation of quails: Review:}

\begin{abstract}
The objective of this article to review the influence that environment plays in creating quail. The animal welfare has occupied a prominent place in farms since stress situations lead to a physiological state that is characterized as undesirable. The temperature and microclimate in the authoring system can be considered as physical factors having the greatest effect on the growth of quails, influencing directly on the feed use. Thermally stressed animals cannot efficiently take advantage of the nutrients provided by the diet, decreasing feed intake. To evaluate the thermal environment in which the animals are exposed, we use the Temperature Index Black Globe Humidity. Indexes vary in temperature and humidity caused by environmental conditions, reflect the change in the average surface temperature by modifying the physiological response of the animal. The vent temperature of the bird can also be an interpreted to identify conditions of comfort or thermal stress measurement representing the temperature of the body core. During heat stress, physiological, hormonal and molecular adjustments occur, causing modifications in function and structure of cells.
\end{abstract}

Key words: Coturniculture, thermal comfort, performance, production.

\section{Introdução}

O aumento da competição entre os mercados têm pressionado o setor zootécnico quanto à melhoria da qualidade na carne e ovos de aves, bem como oferecer soluções que evitam estresses causados pelas variáveis ambientais, proporcionando situações que favoreçam o desempenho dos animais.
Em cada região, têm-se desenvolvido criações econômicas para o produtor e que ofereçam conforto para os animais, não descartando elementos importantes como a aclimatação do plantel e as condições climatológicas (Nääs \& Silva, 1998). 
Segundo Padilha et al. (2001), é obrigatório atentar para os quesitos que regem as oscilações climatológicas, uma vez que estas alteram as respostas clínicas, fisiológicas e comportamentais, que são diretamente associadas ao resultado na criação.

As principais alterações clínicas que o microclima do sistema de criação pode acarretar são as modificações nos parâmetros fisiológicos relacionados com a frequência cardiorrespiratória, influenciando diretamente no equilíbrio térmico das aves, como aumento da temperatura cloacal, cansaço e ofegação. Phillips (1985) e Silanikove (2000) demonstraram que alterações térmicas nos animais podem sugerir uma baixa condescendência a situações extremas relativas ao ambiente.

Baêta \& Souza (1997) afirmaram em suas pesquisas que o ambiente ideal deve ser respaldado por informações que determinem diversas variáveis tais como temperatura, umidade relativa, ventilação e radiação, as quais interferem nodesempenho dos animais.

Situações em que há um baixo gasto de energia em aves, como codornas de corte, significam que a taxa metabólica é mínima, de maneira que o equilíbrio térmico seja mantido sem que haja estresse termorregulatório, de forma que as variáveis climáticas podem ser direcionadas para maximizar o rendimento do animal e sua vida produtiva.

Vários benefícioscomo condições contínuas de bem estar e desempenho acentuado podem ser alcançados com o aprimoramento de estudos referentesà influência que o ambiente exerce em aves, como codornas de corte, traçando formas apropriadas de manejo e programas de alimentação, reduzindo assim, os custos de produção.

Diante do exposto, objetivou-se revisar o estudo da influência que o ambiente exerce na criação de codornas de corte, envolvendoos parâmetros que estão ligados na produção desta espécie.

\section{Coturnicultura no Brasil e no mundo}

A produção e o consumo de ovos de codorna cresceu de forma rápida nos últimos anos (Fridrich et al., 2005), isso porque é uma viável opção para a alimentação humana, bem como sua carne (Oliveira et al., 2002).
A criação de codorna (carne e ovos) tem importância relativa em vários países. No Brasil e no Japão, é intensa a produção de ovos; na França, Itália, Espanha e Grécia, a produção de carne (Murakami \& Furlan, 2002). Esses autores afirmam que nos últimos quarenta anos, países como a China, Polônia, Arábia Saudita e Estados Unidos (Sudeste) desenvolveram a criação comercial de codornas.

O estado de São Paulo é o maior produtor de codornas no Brasil, cerca de dois milhões de aves entre os pequenos, médios e grandes criadores. A Bahia ocupa o sétimo lugar, com cerca de 230 mil aves entre pequenos e médios criadores (Fujikura, 2002).

A coturnicultura foi moldada em cima de muitos cruzamentos efetuados principalmente nos países orientais, onde foi utilizada uma subespécie oriunda da Europa, considerada selvagem, a Coturnix coturnix (Luz, 2002).

Vários fatores levaram as codornas a apresentarem grande importância econômica, tais como fertilidade e prolificidade, características estas atreladas às excelentes taxas de postura e principalmente, ao fato de exigirem pequeno espaço para instalação do plantel.

Conforme descrito por Silva et al (2011), o Brasil, quanto à coturnicultura de corte, apresenta importância no comércio mundial incluindo a sua produção entre os primeiros países, perdendo apenas para a França, Espanha e China, respectivamente. É o segundo maior produtor de ovos, havendo um vertiginoso crescimento em diversas regiões do país e um processo mercadológico diferenciado para a venda tanto de ovos quanto dos cortes comerciais.

Embora no Brasil a coturnicultura seja uma atividade contemporânea, esta já se mostra expressiva principalmente quanto ao fornecimento de animais para corte, de linhagem europeia e que se adequam melhor à produção comercial de carne; estes animais apresentam em média, um peso cerca de 150 a $200 \mathrm{~g}$ maior que as aves de postura, plumagem com coloração mais forte, temperamento mais dócil e ovos nitidamente maiores; apesar de a espécie Coturnix coturnix japônicaser a mais conhecida, utilizada principalmente para a produção de ovos devido às boas taxas reprodutivas e ao baixo peso corpóreo (Oliveira, 2001).

A coturnicultura já se apresentou como um exercício de cunho doméstico, entretanto as 
mudanças no setor da avicultura têm mudado o caráter da produção devido a modernização da cadeia e a implementação de ferramentas tecnológicas que objetivam principalmente uma melhoria na produção em termos numéricos de forma que esta atividade passou a se mostrar como uma das muitas possibilidades na pecuária que apresentam retorno financeiro garantido e rápido.

Segundo Fletcher et al. (2000) e Silva et al. (2009), a demanda por carne de codornas tornou a atividade altamente rentável e bastante favorável ao consumo humano devido as suas características sensoriais e organolépticas e aos fatores nutricionais. Cunha (2009) ressalta que a carne dessa ave apresenta excelentes fontes de aminoácidos e baixas taxas de ácidos graxos.

\section{Bem estar e estresse térmico}

O bem estar animal tem ocupado lugar de destaque nos criatórios uma vez que situações de estresse levam a um estado físiológico caracterizado como indesejável visto como sofrimento, refletindo na conversão alimentar (Jones, 1996). Nos sistemas de criação intensivos que seguem os moldes da exploração moderna, cujo objetivo é o máximo de rendimento, muitos fatores estressantes são visíveis e propiciados por uma gama de motivos como a superlotação do criatório, falhas relacionadas aos programas nutricionais, ventilação inadequada, água de má qualidade ou em quantidade insuficiente e alterações edafoclimáticas (Macari \& Furlan, 1999).

Segundo Furtado et al. (2003), a principal característica de bem estar das aves é imposta em seu local de vivência, bem como o ambiente estar em condições termo neutras. Essas condições variam de acordo com a espécie e dentro da mesma espécie animal, bem como variação da temperatura ambiente, radiação, umidade e velocidade do ar.

$\mathrm{O}$ estresse térmico tem merecido um alerta notável, pelas profundas perdas que ocasionam nos criatórios, neste caso, observam-se três respostas diferentes, a primeira é comportamental onde as codornas se alteram de acordo com a exposição térmica do ambiente; a segunda é autônoma, envolvendo diversas funções fisiológicas como pressão sanguínea e a terceira resposta que é considerada adaptativa abrangendo alterações hormonais (Silva, 2000).
Quanto às respostas neurológicas, elas influenciam na produção de hormônios hipotalâmicos, os quais são responsivos ao calor, sendo estes hormônios desencadeados mais ativamente quando a temperatura corporal aumenta, induzindo o animal a ter respostas de perda de calor de maneira a regular a temperatura corpórea (Macari et al., 2002).

Segundo Vargas \& Motta (2007), o estresse ocasionado pela alta temperaturadiminui $o$ consumo e, consequentemente, a digestão do animal, interferindonoaproveitamento dos alimentos e, nesse sentido, diminuio conteúdo de nutrientes disponíveis para a síntese de tecidos corporais, prejudicandosignificativamente $\mathrm{o}$ desempenho animal.

As aves em crescimento sob estresse por frio mantêm o consumo de alimento, gerando incremento calórico, porém, a energia que serviria para deposição tecidual, em grande parte é utilizada para mantença, diminuindo assim o desempenho. $\mathrm{O}$ estresse por frio inibe o consumo de ração em aves recém-nascidas e jovens, gastando reservas para a termogênese e influenciando negativamente no desenvolvimento anatômico-fisiológico. Isso reflete no desenvolvimento dos animais durante as demais fases de criação, resultando em queda de produtividade, perda de peso e piora na conversão alimentar (Almeida, 2010).

Animais em estresse apresentam modificações metabólicas expressas por alterações bioquímicas e comportamentais, que pelo ponto de vista de Sousa (2013), merecem ser mais bem estudadas. Conhecendo melhor como a temperatura afeta o desempenho das codornas, o produtor poderá lançar mão dos sistemas de criação que proporcionem maior conforto térmico às aves alojadas em um ambiente térmico específico (Sousa, 2013).

A coturnicultura no Brasil apresenta diversos desafios a serem contornados, pois apesar dos melhores resultados produtivos que são obtidos em função das condições tecnológicas, profundas modificações de clima e temperatura registradas nos últimos anos em diferentes partes do mundo também devem ser consideradas. Dessa forma, as altas temperaturas verificadas em distintas regiões, como no nordeste do Brasil, concedem muitas vezes alterações na execução do manejo de maneira que essas ações reflitam em um desempenho animal otimizado. 


\section{Caracterização térmica do ambiente}

A energia térmica em condição diminuída ou elevada presente no corpo da ave representa processos de termólise e termogênese, respectivamente (Silva, 2000).

As codornas são animais homeotérmicos, ou seja, mantém a temperatura corporal relativamente constante, se valendo de estratégias fisiológicas e comportamentais para manter seu bem estar. Entretanto, quando se encontra em desconforto térmico, as aves apresentam uma perda de energia, culminando com uma diminuição da produtividade em função de oscilações da temperatura. Nesse sentido, o plantel prefere minimizar a perda energética diminuindo qualquer tipo de atividade física, inclusive o consumo de ração.

A temperatura e o microclima no sistema de criação podem ser considerados como fatores físicos de maior efeito sobre o crescimento das codornas, influenciando diretamente sobre o aproveitamento do alimento (Gonzales, 1994).

Fisiologicamente, os mecanismos envolvidosna produção extra de calor nos animais, demonstram que aves expostas ao calorapresentam muito mais tecido adiposo (Chwalibog \& Eggum, 1989; Ainbaziz et al., 1993), o que é indicativo de uma taxa metabólica reduzida, enquanto que as aves geneticamente magras pareceram ser maisresistentes acondições adversas de calor, mostrando melhores ganhos de peso e melhor eficiênciaalimentar.

Embora a relação entre ambiente e produção de calor por parte das codornas não apresente um caráter linear, pode-se observar que mantidas em temperaturas mais baixas, há um aumento da exigência de energia. $\mathrm{O}$ estresse térmico promove alterações na capacidade de digestão das aves, interferindo sobremaneira na síntese dos tecidos e consequentemente, o desempenho dos animais (Geraert et al.1993).

Um meio de melhorar o desempenho destes animais em temperaturas adversas seria reduzindo a carga metabólica, ou seja, diminuindo a ingestão de proteína bruta associada ao consumo da ração, valendo lembrar que o incremento calórico associado à digestão e ao metabolismo proteico é muito expressivo, acarretando como resultado um aumento do calor corpóreo (Macleod, 1997).

Curtis (1983) e Esmay \& Dixon (1986), retratam que aqueles animais destinados à produção zootécnica quando se encontram fora da zona de conforto térmico, podem ser prejudicados quanto o seu desempenho. Por outro lado, animais submetidos a ambientes termoneutros aproveitam melhor os alimentos (Fialho et al., 2001).

De acordo com Rostagno et al. (2000), Toledo (2000) e Baêta \& Souza (1997), nutrientes que possuem maior aproveitamento pela codorna, como aminoácidos essenciais, ocasionam um melhor desempenho e bem estar, sendo minimizados, proporcionalmente, à medida que ocorre o aumento da variável temperatura.

Macari et al. (2004) enfatizam em suas pesquisas que a umidade relativa alta impossibilita que a ave elimine calor através da respiração, sendo este um grande paradigma para seu desconforto térmico.

Uma forma de ocorrência de trocas de temperaturas dos animais com o meio ambiente são as trocas sensíveis (radiação, condução e convecção), necessitando de um diferencial de temperatura (gradiente térmico), e outra, são as trocas latentes, principalmente, a evaporação, refletida na ave como forma de ofegação (Silva, 2008).

Animais estressados, principalmente devido a altas temperaturas, não conseguem aproveitar de forma eficiente os nutrientes oferecidos pela alimentação, obtendo como resultado final, uma digestibilidade mais baixa (Bonnet et al., 1997), reduzindo a eficiência do trato gastrointestinal, desde o proventrículo até o íleo como observado também nos trabalhos de Savory et al. (1986).

Dale et al. (1979) conseguiram demonstrar em suas investigações que as aves que são expostas a microclimas com temperaturas altas podem até não diminuir o consumo de ração, entretanto, apresentam uma conversão alimentar prejudicada, com baixo aproveitamento dos micronutrientes quando comparadas aos animais mantidos em ambiente considerado termoneutro. Geraert et al. (1996), corroboram com a ideia de que estes animais, ao tentarem buscar alternativas de dissipação do calor corpóreo, diminuem a eficiência do desempenho em função do excessivo gasto de energia.

Plavnik (2003) mostrou em suas pesquisas que a oxidação da proteína excedente também gera calor, reiterando a ideia pressuposta por Miltenburg (1999) que preconiza a formulação de rações levando em consideração a proteína ideal 
para cada fase do sistema de criação, obtendo assim uma melhor conversão deduzindo uma diminuição do estresse térmico.

Para avaliar o ambiente térmico em que os animais estão expostos, levando em consideração maior números de fatores climáticos possíveis, como radiação, temperatura, umidade relativa e velocidade do ar, utiliza-se o Índice de Temperatura de Globo Negro e Umidade (ITGU) proposto por Buffingtonet al. (1981).

Embora seja escassos estudos de faixas de temperatura de conforto térmico para codornas de corte, Sousa et al. (2014) verificaram que o melhor desempenho obtido dessa espécie foi encontrado quando estavam mantidos em ambientes entre 36 e $39^{\circ} \mathrm{C}$ e valores de ITGU entre $87,1 \pm 0,4$ e $91,4 \pm 0,6$ para a primeira semana; 30 e $27^{\circ} \mathrm{C}$, e valores de ITGU entre 75,8 $\pm 0,4$ e $79,9 \pm 0,6$ para a segunda semana; $24^{\circ} \mathrm{C}$ e valores de ITGU de 70,8 $\pm 0,5$ para a terceira semana; $26^{\circ} \mathrm{C}$ e valores de ITGU 75,3 $\pm 0,7$ para a quarta semana e $25^{\circ} \mathrm{C}$ e valores de ITGU 75,8 $\pm 0,9$ para a quinta semana.

A temperatura cloacal das aves também pode ser uma medida interpretada para identificar condições de conforto ou estresse térmico, representando a temperatura do núcleo corporal, uma vez que os animais têm como objetivo primário controlar sua temperatura interna, posteriormente, controlar a sua temperatura superficial. A temperatura cloacal pode medir, também, o grau de adaptação das aves sob condições ambientais adversas (Brown-Brandtl et al., 2003).

Filho (2011) ao medir a temperatura cloacal de codornas japonesas submetidas a diferentes ambientes, não encontrou diferenças significativas, permanecendo valores próximos de $40,5^{\circ} \mathrm{C} \pm 0,05^{\circ} \mathrm{C}$. Nesse sentido, foi considerado por ele como valor associado à condição de conforto térmico.

Para avaliar se as aves se encontram em situação de conforto térmico ou não, Richards (1971), propôs uma equação da temperatura superficial média das aves (TSM) (1) e outra para a predição da temperatura corporal média (TCM), eq. (2):

$\mathrm{TSM}=(0,12 \cdot$ Tasa $)+(0,03 \cdot$ Tcabeça $)+$ $(0,15$.Tpata $)+(0,70$. Tdorso $)(1)$

$\mathrm{TCM}=(0,3 \cdot \mathrm{TSM})+(0,7 \cdot$ Tcloacal $)(2)$
Richards (1971) propôs esse modelo estudando três lugares da ave que possuem penas tais como asa, dorso e coxa e três lugaresque não possuem penastais como pata, crista e dedo, e atribuiu pesos para cada região, de acordo com a área superficial de cada uma delas. Este autor observou queas regiões corporais que causaram mais efeitos foram a asa, cabeça, pata e dorso, com seus respectivos pesos descritos pela eq. (1).

\section{Efeitos do estresse por calor sobre aspectos fisiológicos e produtivos}

A ave submetida a estresse por alta temperatura demonstra em sua fisiologia, o desenvolvimento da vasodilatação periférica, em que resulta na evoluçãode perda calórica não evaporativa. Para conseguir aumentar essa perda calórica, a ave exerce o comportamento de aumentar a área superficial, mantendo as asas afastadas do corpo, arrepiando as penas e intensificando a circulação periférica (Macari et al., 2004).

Borges et al. (2003) relatam que a perda calórica não evaporativa também pode ser desenvolvidapela alta produção de urina, que está totalmente ligada na compensaçãodaelevada ingestão de água fria pelas aves.

Outraparticipaçãosignificativa que o estresse por alta temperatura ocasiona nas aves é a diminuição daingestão de ração, sendo neste caso, o desempenho afetado, uma vez que as aves tentam diminuir a produção de calor interno. Aapreensãoe a assimilação dos nutrientes contidos nos alimentos geram energia, sendo esta liberada e representada em forma de calor, caracterizada como incremento calórico (Nascimento \& Silva, 2010).

Quando a ave se encontra em estresse por calor, acontecemmudançasem sua fisiologia (desequilíbrio eletrolítico), hormônios (T3, T4 e corticosterona) e moléculas, bem como na função e na estrutura das membranas celulares (Lin et al., 2006).

Sousa (2013) verificou efeito dos ambientes de criação $\left(24\right.$ e $\left.33^{\circ} \mathrm{C}\right)$ sobre o rendimento de carcaça (\%) e o peso do fígado (g) em codornas de corte aos 35 dias de idade, em relação àquelas mantidas a $25^{\circ} \mathrm{C}$ (termoneutro). Quinteiro Filho (2008) observou menor peso relativo de carcaça de órgãos linfoides (timo e bursa de Fabricius) de frangos de corte de 42 dias de idade, quando submetidos a $32^{\circ} \mathrm{C}$, quando comparados a aves mantidas em ambiente confortável. Este autor 
afirma que a redução dos órgãos linfoides pode causar comprometimento do sistema imune dos animais.

A glândula tireoide causa a modificação no metabolismo da ave, sendo esta glândula responsável na síntese dos hormônios triiodotironina (T3) e tiroxina (T4). Esses hormônios são causadoresdo controle da produção calórica e metabólicadas células dos animais, sendo o T3 mais associadoà termogênese (Cassuce, 2011). Todavia, esta autora afirma que o acúmulo desses hormônios (T3 e T4) no plasma sanguíneo necessitam, além da temperatura ambiental, da linhagem das aves.

Esses hormônios acima têm forte relevância no metabolismo das aves, causando efeito no crescimento e na eficiência alimentar, no consumo de oxigênio, na síntese e o metabolismo de proteínas, carboidratos e lipídeos, assim como a termogênese e a composição corporal (Lawrence \& Foller, 1997).

Aves estressadas por alta temperatura mostram menores acúmulos hormonais (T3 e T4), tendorelação diretacom a diminuição da atividade da bomba de sódio e potássio e o consumode oxigênio realizado pelas células, resultandona diminuição da taxa metabólica (Chen et al., 1994).

\section{Considerações finais}

Com base nesta revisão de literatura, nota-se que apesar de poucos estudos em relação à influência que o ambiente térmico causa em codornas de corte, tem-se a ideia que fisiologicamente, quando comparadas a frangos de corte, podem apresentar baixo desempenho, bem como alterações no rendimento de carcaça e peso relativo de órgãos.

Conclui-se também que as características de parâmetros fisiológicos podem ter valores alterados quando codornas ficam submetidas a condições de temperaturas quentes ou frias em relação a condições termoneutras.

\section{Referências Bibliográficas}

Ain Baziz et al. Does heat exposure modify carcass quality of broilers? In: Proceedings Of The Xith European Symposium On The Quality Of Poultry Meat, 1993. Tours; France: World's Poultry Science Association, French Branch, 1993, vol. I, pp. 52-58
Almeida, E. U. Níveis de lisina digestível e planos de nutrição para frangos de corte machos de 1 a 42 dias de idade. 2010. 43f. Dissertação apresentada ao Programa de Mestrado em Ciência Animal do Centro Universitário de Vila Velha, Vila Velha, 2010.

Baêta, F. C. \& Souza, C.F. Ambiência em edificações rurais - conforto animal. Viçosa: UFV, 1997. 246p.

Bonnet, S. et al. Effect of high ambient temperature on feed digestibility in broilers. Poultry Science, 76 (6): 857-863, 1997.

Borges, S. A. et al. Fisiologia do estresse calórico e a utilização de eletrólitos em frangos de corte .Ciência Rural, Santa Maria, v.33, n.5, p.975-981, 2003.

Brown-Brandtl, T.M. et al. A new telemetry system for measuring core body temperature in livestock and poultry. Applied Engineering in Agriculture, St. Joseph, v. 19, n. 5, p. 583589, 2003.

Buffington, D.E. et al. Black globe humidity index (BGHI) as a comfort equation for dairy cows. Trans. ASAE, St. Joseph, v.24, n. 3, p. 711-714, 1981.

Cassuce, D.C. Determinação das faixas de conforto térmico para frangos de corte de diferentes idades criados no Brasil. 2011. 91p. Tese (Doutorado em Engenharia Agrícola) Universidade Federal de Viçosa, Viçosa, 2011.

Chen, C.L. et al. Effects of heat stress on $\mathrm{Na}+$ ,K+-ATPase, Mg+-activated ATPase, and $\mathrm{Na}+$-ATPase activitiesof broiler chickens vital organs. Journal Toxicology an Environmental Heath, London, v.41, p.345- 356, 1994.

Chwalibog, A. \& Eggum, B. O. Effect of temperature on performance, heat production, evaporative heat loss and body composition in chickens. Archiv fur Geflugelkunde, 53, 119184, 1989.

Cunha, F. S. A. Avaliação da mandioca (Manihot esculenta Crantz) e subprodutos na alimentação de codornas (Coturnix japonica). 2009. 98 f. Tese (Doutorado) - Curso de Zootecnia, Universidade Federal Rural de Pernambuco, Recife, 2009. 
Curtis, S. E. Environmental management in animal agriculture. The Iowa State University: Ames, 1983. 410p.

Dale, N. M. \& Fuller H. L. Effects of diet composition on feed intake and growth of chicks under heat stress. Poultry Science. 58:1529-1534, 1979.

Esmay, M. L. \& Dixon, J. E. Environmental control for agricultural buildings. West port: AVI, 1986 287p.

Fialho, F.B. et al. 2001. Método para comparar curva de produção de ovos usando um modelo matemático. Embrapa Suínos e Aves. p. 1-4 (Relatório Técnico, 293).

Filho, G. F. S. Temperatura corporal de codornas (coturnix coturnix japonica) submetidas a diferentes temperaturas do ar. In: $\mathrm{X}$ Congresso de Ecologia do Brasil, 2011, São Lourenço. Anais... São Lourenço- Minas Gerais: UFLA, 2011. p.1-2.

Fletcher, D. L. et al. The relationship of raw broiler breast meat color and $\mathrm{pH}$ to cooked meat color and pH. Poultry Science. 79:784788, 2000.

Fridrich, A.B. et al. Exigência de proteína bruta para codornas europeias no período de crescimento. Arquivo Brasileiro de Medicina Veterinária e Zootecnia. v.57, n.2, p.261-265, 2005.

Fujikura, W.S. Situação e Perspectivas da coturnicultura no Brasil. In: $1^{\circ}$ SIMPÓSIO Internacional De Coturnicultura, 2002, Lavras. Anais... Lavras: UFLA, 2002.

Furtado, D. A. et al. Análise do conforto térmico em galpões avícolas com diferentes sistemas de acondicionamento. Revista Brasileira de Engenharia Agrícola e Ambiental, v.7, n.3, p.559-564, 2003.

Geraert, P. A. et al. Are genetically lean broilers more resistant to hot climate? British Poultry Science. v. 34, 643-653, 1993.

Geraert, P.A et al. Metabolic and endocrine changes induced by chronic heat exposure in broiler chickens: Growth performance, body composition and energy retention. British Journal Nutritional. Cambridge. 75 (2): 195204, 1996.

Gonzales, E. Síndrome da morte súbita em frangos de corte: papel da nutrição e programas de alimentação. 1994. In:
Conferência Apinco de Ciência e Tecnologia Avícolas. Santos, São Paulo. 1994. p. 249263.

Jones, R.B. 1996.Fear and adaptability in poultry: insights, implications and imperatives. Whitish. Poultry Science. J. 52 (2), 131-174, 1996.

Lawrence, T.L.J. \& Fowler, V.R. Hormonal, genetic and immunological influences on growth. In: Growth of farm animals. New York: Cab International. p. 102 - 149, 1997.

Lin, H. et al. Impaired development of broiler chickens by stress mimicked by corticosterone exposure. Comparative biochemistry and physiology. Party A, Molecular e Integrative physiology. v. 146. p. 400-405, 2006.

Luz, L.C.P. Variação granulométrica do calcário e diferentes níveis de cálcio em rações de codornas japonesas (Coturnix coturnix japonica). Lavras: Universidade Federal de Lavras, 2002. 58p. Dissertação (Mestrado em Zootecnia) - Universidade Federal de Lavras, 2002.

Macari, M. et al. Fisiologia Aplicada a frango de corte. 2.ed. Jaboticabal: Funep/Unesp. 2002. $375 \mathrm{p}$.

Macari, M. \& Furlan, R. L. Estresse por calor e frio em frangos de corte. Anais... In: IV Seminário Internacional em Ciências Avícolas, Santa Cruz - Bolivia, 1999, p.95109.

Macari, M. et al. Aspectos fisiológicos e de manejo para manutenção da homeostase térmica e controle de síndromes metabólicas. 2004. In: Mendes, A. A.; Naas, I.A.; Macari, M. Produção de frangos de corte. Campinas: Facta, 137-156, 2004.

Macleod, M.G. Effects of amino acid balance and energy: protein ratio on energy and nitrogen metabolism in male broiler chickens. British Poultry Science, 38:405-411, 1997.

Miltenburg, G. Avicultura. Avicultura Professional, Bogotá. 17 (9): 33-35, 1999.

Murakami, E.A.; Furlan, A.C. Pesquisa na nutrição e alimentação de codornas em postura no Brasil. In: I Simpósio Internacional de Coturnicultura, 2002, Lavras. Anais... Lavras: UFLA, 2002. p.113-120.

Nääs, I.A.; Silva, I.J.O. Técnicas modernas para melhorar a produtividade dos suínos através 
do controle ambiental. 1998. In: Ingeniería Rural y Mecanizazión Agrária en el Ámbito Latinoamericano. Anais... Balbuena. 464472, 1998.

Nascimento, S. T. \& Silva, I. J. O. As perdas de calor das aves: entendendo as trocas de calor com o meio. 2014. Publicado em: Acesso em: 25/07/2014.

Oliveira, E.G. et al. Desempenho produtivo de codornas de ambos os sexos para corte alimentadas com dietas com quatro níveis proteicos. Archives of Veterinary Science. v.7, n.2, p.75- 80, 2002.

Oliveira, E.G. 2001. Pontos críticos no manejo e nutrição de codornas. In: Simpósio sobre manejo e nutrição de aves e suínos e tecnologia da produção de rações, 2001, Campinas. Anais... Campinas, 71-96.

Padilha, J.A.S.; Toledo Filho, R.D.; Lima, P.R.L.; Joseph, K.; Leal, A.F. Argamassa leve reforçada com polpa de sisal: compósito de baixa condutividade térmica para uso em edificações rurais. Revista Engenharia Agrícola, v.21, n.1, p.1-11, 2001.

Philips, B.W. La cria de ganado em ambientes desfavorables. Roma, Food and Agriculture Organization of the United Nations. 1985. Statistical Analysis System. 6 ed. Cary, NC: SAS Institute Inc., USA, 1985, 429p.

Plavnik, I. A. 2003. Contribuição da nutrição na criação de aves em climas quentes. In: Conferência Apinco de Ciência e Tecnologia Avícolas, 2003, Campinas. Anais... Campinas: FACTA. 235-246.

Quinteiro Filho, W. M. Efeito do estresse térmico por calor sobre os índices zootécnicos, a integridade do trato intestinal e a imunidade inata em frangos de corte.2008. 138f. Dissertação de mestrado em ciências. Universidade de São Paulo. 2008.

Richards, S.A. The significance of changes in the temperature of the skin and body core of the chicken in the regulation of heat loss. Journal of Physiology, Cambridge, v. 216, p. 1-10, 1971.

Rostagno, H.S. et al. Tabelas brasileiras para aves e suínos. Composição de alimentos e exigências nutricionais. Viçosa, MG: Universidade Federal de Viçosa. 2000. p. 141.
Savory, C. J. 1986. Feeding Behavior. In: Boorman, K.N.; Freeman, B. M. Food intake regulation in Poultry. Edinburgh: 1986. LTD. 277-323.

Silanikove, N. Effects of heat stress on the welfare of extensively managed domestic ruminants. Livestock Production Science. 67:1-18, 2000.

Silva, J.H.V. et al. Exigências nutricionais de codornas. In: XXI Congresso Brasileiro de Zootecnia - Zootec. 2011. Maceió: Anais... Maceió - Al, 2011.

Silva, R.G. Introdução a Bioclimatologia animal. São Paulo: Nobel, 2000. 283p.

Silva, R.G. Biofísica ambiental - os animais e seu ambiente. Jaboticabal: Funep, 2008. 386 p.

Silva, V. K. et al. Desempenho de frangos de corte de 1 a 21 dias de idade alimentados com rações contendo extrato de leveduras e prebiótico e criados em diferentes temperaturas. Revista Brasileira de Zootecnia, v.38, n.4, p.690-696, 2009.

Sousa, M. S. Determinação das faixas de conforto térmico para codornas de corte de diferentes idades. 2013. 76p. Tese (Doutorado em Engenharia Agrícola) - Universidade Federal de Viçosa, Viçosa, 2013.

Sousa, M. S. et al. Determinação de limites superiores da zona de conforto térmico para codornas de corte aclimatizadas no Brasil de 22 a 35 dias de idade. Revista Brasileira de Saúde e Produção Animal, Salvador, v.15, n.2, p.350-360, 2014.

Vargas, J. G. \& Motta, R. R. Produção de aves em clima quente. Boletim técnico. Junho, 2007. 78 Edição.

\section{Recebido em Agosto 5, 2014 \\ Aceito em Setembro 23, 2014}

License information: This is an open-access article distributed under the terms of the Creative Commons Attribution License, which permits unrestricted use, distribution, and reproduction in any medium, provided the original work is properly cited. 